\title{
How to Integrate Recent Development in Technology with Digital Prototype Textile and Apparel Applications
}

\author{
Evridiki PAPACHRISTOU, Nikolaos BILALIS \\ Technical University of Crete, Department of Production Engineering and Management, Crete, Greece
}

\begin{abstract}
The textile and clothing industry is moving away from its traditional roots in an attempt to revive the fortunes of this mature industry, through the adoption of novel technologies. Digital Prototypes are used as an essential tool in the modern design process. The integration can speed up the design process and affect competition be-tween companies. Typical applications are digital textile and fashion design, pattern generation to custom-design clothing, fitting evaluation, style editing, and virtual try-on. However, new product developments in textiles and clothing have widened our views of the world and must also be covered. The ever-growing spectrum of smart textiles and wearable technologies has the potential to take the textile industry in a completely new \& sustainable direction, far beyond its traditional roots. The integration of smart functionality into clothing and other textile products into the digital prototype is essential in order to alter our relationship with them and the way we use them.
\end{abstract}

Keywords: Digital Prototype, apparel, virtual try-on, technology integration, new product development model.

\section{INTRODUCTION}

The global textile, clothing and fashion (TCF) industries are one of the most competitive and skilled-labour dependent industries with growing complexities and market dynamics related to globalisation and competition. Moreover, differentiation has become a key aspect in developing competitive advantage for these TCF firms owing to greater market dynamics, rapid fluctuations in postmodern consumer behaviour, shortening of fashion product life-cycle, product proliferation to mention a few [1].

More recently, [2], mentioned that the traditional apparel product development process is a typical iterative 'optimisation' process that involves trial-and-error. In order to confirm the design and achieve a satisfactory fit, a number of repeated cycles of sample preparation, trial fit-ting and pattern alteration must be conducted. The process itself is time-consuming, costly, and dependent on the designer's skills and experience.

An additional factor in TCF is that garments are beginning to absorb communications technology, and IT systems are becoming embedded in the clothing we wear. Technologists use state-of-the-art materials to make computer parts lightweight and portable and the wearer feel revitalised and refreshed, while fashion designers apply tailoring principles to integrate them into clothing. As Quinn states [3], interactive media is changing the way we live and relate to one another, but soon it will transform the way we use our clothing.

In the fast-approaching future, the equity value of fashion companies will be based, not on how many products they sell, but on the quality of their software. The adoption of novel technologies will attempt to revive the fortunes of this mature industry moving it away from its traditional roots.

Digital Prototypes are used as an essential tool in the modern design process. The integration can speed up the design process and affect competition between companies. However, this technology will not replace the aesthetic appeal of great products, the magnetic attraction of great brands, or the advantages of extended portfolio assets, because the fashion industry will continue to build great products, brands and businesses as it has done successfully in the past. But technology will, indeed, replace products, brands and financial strategies as the key source of value creation [4].

In this paper we present the technologies for the digital prototyping in TCF, the recent trends in TCF in smart materials and we discuss their integration in the digital prototyping process.

Corresponding Author: Evridiki PAPACHRISTOU, Tel: +30 2821036250, E-mail: evridik_p@yahoo.com

Submitted: 15 October 2014, Revised: 04 March 2015, Accepted: 01 July 2015 


\section{DIGITAL PROTOTYPING IN TEXTILE, CLOTHING \& FASHION INDUSTRY}

Digital or Virtual prototyping (VP) is a process used for shortening the time to market and reducing the product cost. It allows designers to experiment easily with a variety of fabrics and patterns on a 3D virtual body before the actual garment is manufactured; it makes use of a digital model, for testing and evaluating the specific characteristics of a product and for simulating the manufacturing processes in a computational environment [5]. The realistic simulation of the mechanical behaviour of cloth was the first focus; however virtual garment simulation soon evolved toward the simulation of virtual garments on synthetic characters. Although industries like computer graphics, entertainment and electronic commerce reap the most obvious benefits from cloth simulation on animated virtual characters, virtual prototyping of garment models can be a real benefit for the garment industry: visualizing a garment without actually making it drastically simplifies the prototyping phase [6].

\section{$2.1 C A D / C A M$}

As mentioned above, the clothing industry is the most skilled labour-dependent industry and any cost saving through new computer-aided design (CAD) technologies has become a requirement in gaining a competitive advantage.

Garment CAD technology is the use of computer as a tool to assist the design process of a garment product. It is given that $\mathrm{CAD}$ is a mainstream tool and companies that hope to compete in the fashion marketplace, especially at the mass level, cannot prosper without some level of CAD technology. Compared to other mechanical product, garment CAD has to address some special issues:

- Instead of using rigid solid objects, fashion industry deals with soft material with low bending stiffness

- The conventional assembly methods of other industries do not apply to the product of a gar-ment where some parts like collar, sleeve, are assembled together following specific pattern-making rules [7].

- Garment industry, depends on 2D patterns for manufacturing but the quality of fit is evaluated on 3D human models. Based on these observations, garment $\mathrm{CAD}$ is a unique research area that has attracted considerable attentions.

\subsection{Digital Textile and Fashion Design}

Although the management of digital colour in the TCF industry has been around for many years, it has been only in recent years that commercial systems have provided integrated solutions linking all the parties involved in the supply chain like designers, buyers and technologists. It has become possible to re-think the whole process of product development by specifying col-our digitally at the outset of the product development process. According to [9], digital printing of textile materials can provide sample lengths of the right colour (and visual texture) for proto-typing and photo shoots. This offers the possibility of shortening lead times for product development and maintaining confidentiality about products until decisions to order bulk have been made. [10], in particular believes that digital technologies allow fabric print designers to work concurrently with apparel designers. If a new fabric print can be simulated on screen in minutes and in the design room in less than 24 hours, then the timeconsuming task of developing samples is greatly reduced.

\subsection{Pattern Generation to Custom-Design clothing}

The TCF industry has been adopting digital 3D technologies applied to try-on stages by using body scanners and are now foreseen fitting of tailor-made garments. According to [11], an essential key to the use of these enabling technologies is the ability of Computer-Aided-Design (CAD) systems to integrate measurement information and make changes to patterns, as necessary, without permanently changing the basic, original garment pattern (Figure 1). In 2008, [12] proposed an interactive co-evolutionary CAD system for GPD (ICE-GCAD) because they believed traditional CAD (Computer-Aided Design) methods in garment pattern design (GPD) fail to utilise the knowledge of experts for inexperienced designers.

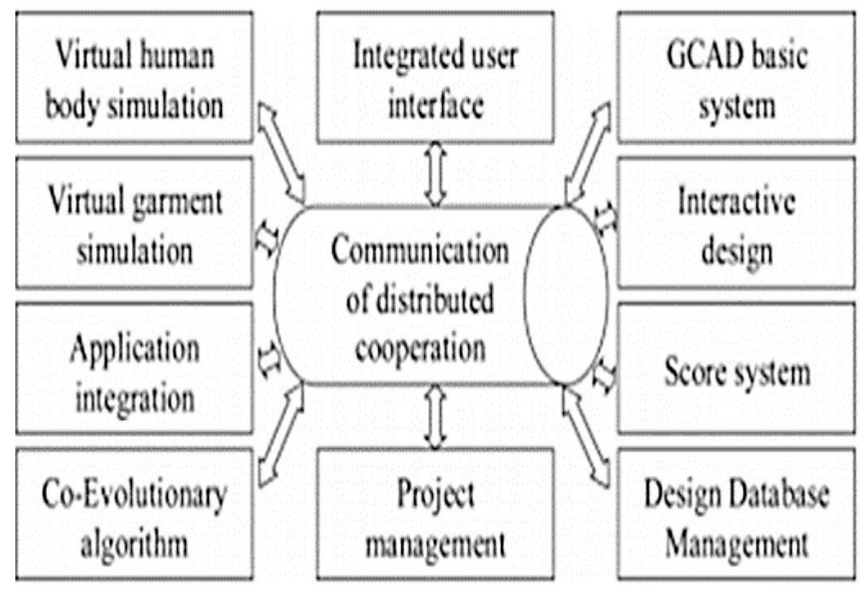

Figure 1. Functionality model of Interactive Co Evolutionary-GCAD, Source: [12] 
Moreover, the study of [13] aimed to reduce the time and human resource costs involved in the process of garment development and to pursue the objectives of fittingness of clothing and the display of graceful figures by reversing design procedures. They presented a knowledge-based system with a flattening method for developing 2D basic patterns from 3D designed garments.

\subsection{Draping \& Fitting Evaluation}

Another critically important parameter in the application of body scanning, mass customisation, computer-aided design and computer-aided manufacturing (CAD-CAM) and automatic pat-tern making to clothing design and manufacturing is drape modelling - drape and the dominant role of fabric mechanical properties. In recent years, the most significant developments have been the empirical prediction and modelling of drape as well as the move towards 3D design, simulation and virtual modelling (3D virtual prototyping). Several 3D fashion design systems have been developed with online interface that take several sizes and re-drape them on a custom model to allow for trying on clothes online. These interfaces enable the designer to 'drape and validate' their design onto a computer generated manikin or one built off a body scan of a fit model, taking into account technical information, fabric type, colour, drape, tensile, shearing, bending as well as the effect of seams [8]. [6] \& [14] have proposed many deformable cloth models for efficient garment draping and animation with which the customers can visualise the realism of virtual tryon. In addition, fuzzy-logic systems have been developed and used to help to improve a wearer's perception of the fit of a garment and to achieve a balance between the style of garments and the comfort of the wearer [15]. However, according to [16] such a balance is difficult to achieve using existing pattern generation methods because these methods cannot provide suitable estimations.

\subsection{Style Editing}

In the traditional fashion product development cycle, designers often adjust 2D patterns to produce clothing with better fit for individual customers, who often do not have 'ideal' body shape and possess a few 'abnormalities' in one or two areas of the body. In addition to 2D pat-tern alteration, tools are developed for 3D based interactive style editing. Users can drag the feature curve or boundary of the $3 \mathrm{D}$ garment directly to alter the garment size. In most CAD application, freeform deformation is used for 3D garment editing, the edited results cannot be accurately reflected on 2D patterns, because distortion free flattening method is still not yet available[17]. Proposed a novel method for 3D-based editing allowing direct style editing for fit improvement in $3 \mathrm{D}$ space, and directly projecting results on the pattern alteration in $2 \mathrm{D}$ plane.

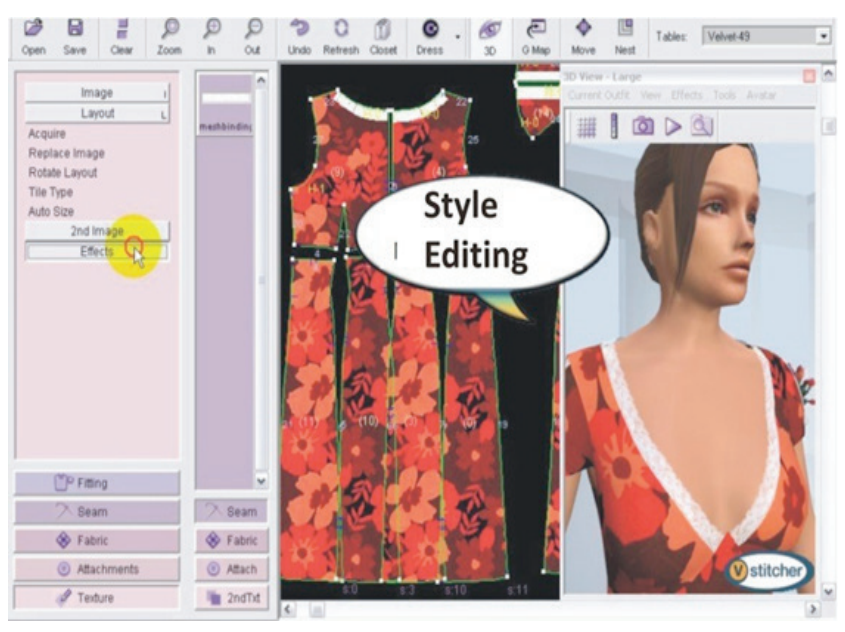

Figure 2. V-Stitcher 3D Style editing

Source: http://www.browzwear.com/products/v-stitcher/ retrieved on 18 July 2014

\subsection{Virtual Try-on}

Fontana et al [18] presented a physics-based system for virtual cloth design and simulation expressly conceived for design purposes. The integration of these models within CAD systems for garment design leads to highly accurate cloth shape results for virtual prototyping and quality evaluation tasks.

The fashion industry welcomes the concept of designing the garment directly in 3D. The aim is to have more flexibility in the way the samples and prototypes are begin made, by reducing the prototyping cycle time and significantly simplify the process that currently relies on physical samples and fit sessions. However, the current garment development process should not be changed completely, but instead embrace the new 3D practical tools and make them fit in the existing development process. In some respects the new 3D CAD systems are expected to mimic the physical process of prototyping and turn it to a digital process with all its benefits, including the successful control of communication, final product and delivery schedule across global partners 
[19]. Developed a collaborative virtual prototyping platform linking 3D CAD to traditional 2D CAD and PDM (Product Data Management) systems (Figure 3) [19].

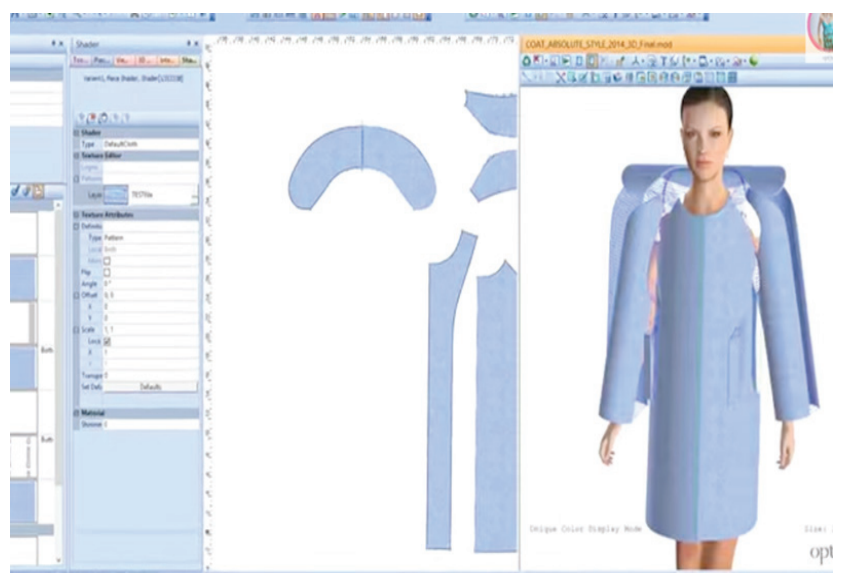

Figure 3. Optitex 3D Virtual Product Development (2D to 3D approach)

Source: http://www.optitex.com/en/Virtual-Product-Development retrieved on 18 July 2014

With this platform, they provide an on-line access to specialised services, such as a fabrics library, an on-line cost estimation facility, and a real-time interactive animation service (animated virtual try - on of different garment sizes on different body sizes and shapes). Their objective was to reduce 'time to-design', reduce proto-typing costs and provide an efficient e-collaboration environment for multiple actors involved in product development.

Although, as it was mentioned above, the fashion industry is slow to embrace the virtual modelling due to the challenging material of the fabric, many see the revolution coming. The developers of Fashion 3D modelling systems offer new and more convenient tools and the effect of reality is becoming more and more convincing. Although computer systems significantly facilitate the development of a product, the knowledge and skill of the user are still very important. The main problems are connected with defining the connectable layers, determination of tuck-up and roll-up parts of a garment, characterisation of the multi-coloristic qualities of a fabric, the thickness of layers and the position of padding (Figure 4) [20].

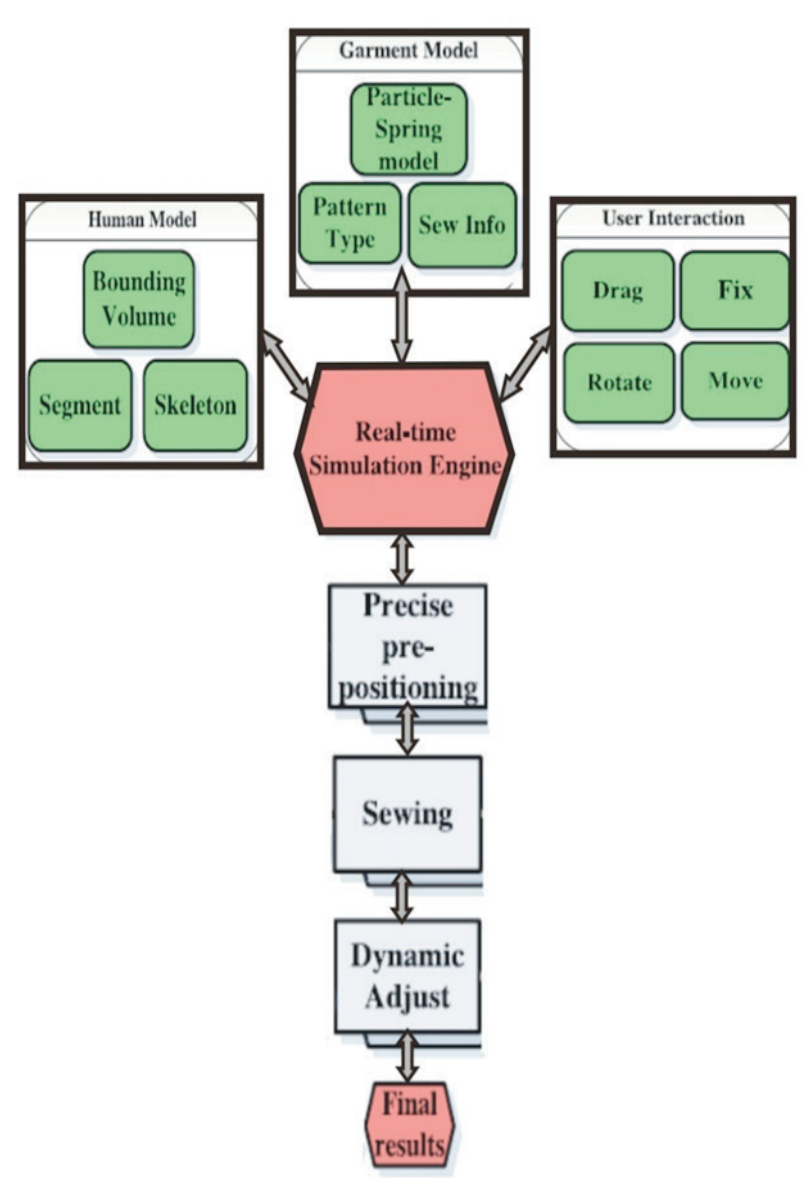

Figure 4. Outline of interactive virtual try-on system.

\section{RECENT DEVELOPMENT IN T\&C}

In the field of textiles, innovation has resulted in a wide range of natural and synthetic fabrics that are lighter, smarter, multifunctional and with a wider range of engineered properties [21]. Research on smart and intelligent textile began at the end of the 20th century, and it has made a quantum leap in the 21 st century.

Wearable technology involves integration of electronics into clothing, watches and even bodies. The adoption of a new generation of smart textiles and wearable technologies opens up new possibilities for developers and gives the potential to enhance functions like heat regulation, impact protection, communication, antimicrobials, and fire protection etc. of a multipurpose garment layering system to suit the lifestyle needs of the wearer [22]. Current day innovations create significant demand and scope on creative capability in the clothing industry, leading to functional clothing. These functional garments exhibit a marked difference in its 
performance \& aesthetic appeal which has a massive impact on today's fashion trends. As [23] points out, what makes smart fabrics revolutionary is that they have the ability to do many things that traditional fabrics cannot, including communicate, transform, conduct energy and even grow.

Clothing and electronics have traditionally been separate industry sectors and the current need for cross-disciplinary synergy between fields of fashion, design, and technology science, has caused problems [24]. Other researchers like [25] also mentioned that smart clothing is a combination of new fabric technology and digital technology, which means that the clothes are made with new signal-transfer fabric technology with installed digital devices but they didn't focus on any roused problems. Instead they concluded that this combination, meet all criteria of high-added value technology allowing transformation to a competitive hightech industry: from resource-based towards knowledgebased; from quantity to quality; from mass-produced singleuse products to manufactured-on-demand, multi-use and upgradable product-services; from "material and tangible" to "intangible" value-added products, processes and services. According to [26] these clothing products will eventually be essential to the near future lifestyle (Figure 5).

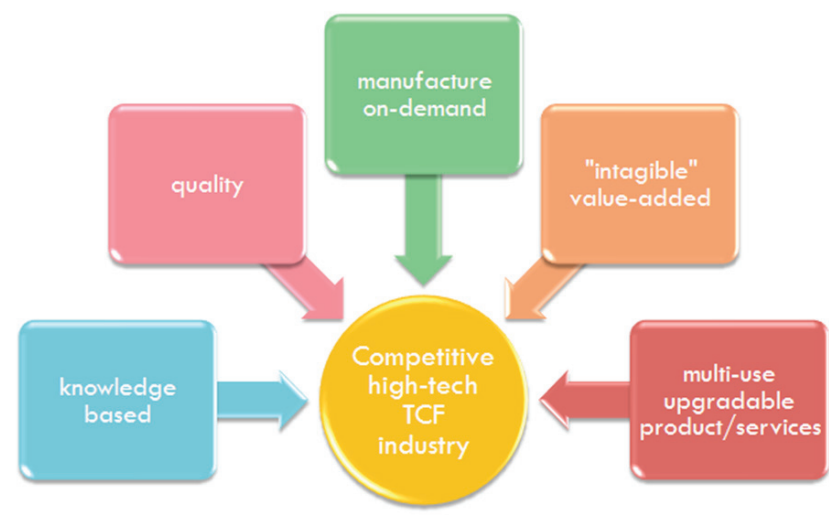

Figure 5. Transformation of the TCF industry

They agree that smart clothing is the convergence of the textile/clothing and digital industries. As the combination between these two industries brings large opportunities and benefit, many institutions, organisations, and enterprises have paid great attention and planned significant investments. However, the standardisation of smart clothing technology has rarely been considered and little research has focused on solving these problems.
It is expected that this integrated technology will proceed from block-based technology to embedded technology, and accordingly to move technology from textile converting to fibre level. Therefore, novel fibre materials such as ICPs and new technologies such as nanotechnology and electro spinning will play an important role in the next-generation material/technology [27]. According to [28], advanced tools and materials are making the designer's task even more complex. Designers need to consider the real need and ease of use in terms of functionality, positioning, compatibility, maintenance and aftercare, and the clarity of the interface between the technology and the user. Therefore as a new industrial revolution takes place, with technical textiles and electronics industries merging, training and support is required in order to approach TCF from a more product design user-driven perspective.

\subsection{How to Integrate Them with Digital Prototype}

Fashion trends and technology providers will lead in the future the rapidly growing older TCF community. The cross-disciplinary product development team of the future needs to be consisted of a new breed of designers who share a new "common" language" to bridge traditional boundaries between the cultures of technical textiles and clothing, wearable electronics and ICT-based systems, social and health sectors. This team will provide the market with smart customised, value-added, usable and attractive products (Figure 6).

Different users from pattern makers to garment manufacturers can be a part of a promising real-time collaborative product development environment for 3D CAD data sharing and manipulation. In this environment, multi-national manufacturing companies can develop, view, manipulate, analyse, and integrate product designs on the basis of supporting interactive collaborative design and manufacturing activities [7].

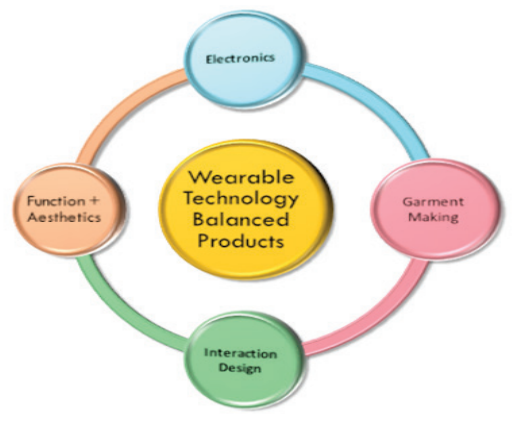

Figure 6. Parallel activities/multidisciplinary collaboration for smart clothing products 
Some researchers in clothing and textile design have asserted the importance of multidisciplinary collaboration, and suggested development processes for smart clothing products $[25,27,29,30]$.

Until every part of technology can be made of textile material without any functional limitation, technical components cannot be completely integrated into the clothes [31]. Therefore, it should be simplified, invisible, attractive and fashionable [32], mentioned that the prototyping process consists of three parallel activities: electronics, garment making and interaction design; those three activities are strongly connected to each other. Thus, wearable technology projects are done in collaboration with different groups from different fields of research (varying from fashion to engineering) in order to create balanced products in function and aesthetics (Figure 7) [27]. Suggested that a new product design model is needed to enhance understanding about the work and communication with collaborators.

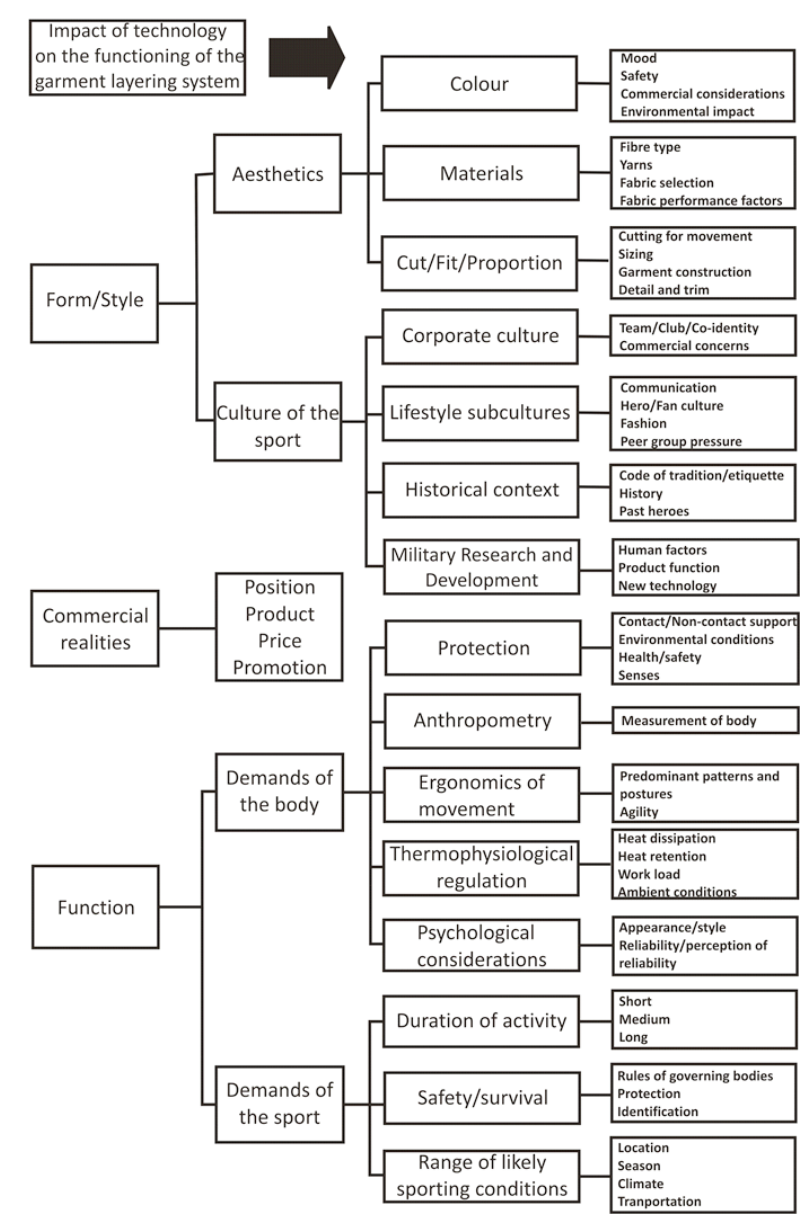

Figure 7. The start of a process tree for examining the codesign area of smart clothing and wearable technology [22]

\section{CONCLUSION}

Some researchers believe that the available technology in the conceptual and design phases of fashion products development is proving that digital prototype is feasible and can be used for some specific goals and applications. Others state that unless the digital prototype integrates successfully and elegantly in the entire product development cycle-from design and development to marketing and sales applications, the process cannot accelerate in an efficient and effective way, ensuring a massive competitiveness in the market.

The product development process is a cycle which is related to large group of people. Digital prototype in the textile and clothing industry enables technologies in the process of product development where various operators are involved in the different stages, with various skills and competencies, and different necessity of formalising and defining in a deterministic way the result of their activities. Taking into account the recent trends in TCF, the product development cycle and the use of VP cannot be restricted in the "typical cycle" but additional tools and skills are required to be integrated taking into account these developments.

\section{REFERENCES}

[1] Pal, Rudrajeet, and Håkan Torstensson. "Aligning critical success factors to organizational design: A study of Swedish textile and clothing firms." Business Process Management Journal 17, no. 3 (2007): 403-436.

[2] Meng, Y, C Wang, and X Jin. "Flexible shape control for automatic resizing of apparel prod-ucts." ComputerAided Design 44, no. 1 (2012): 68-76.

[3] Quinn, Bradley. Fashion Futures. London: Merrell Publishers, 2012.

[4] Beltramini, Enrico. "The Companies with the Best Software Will Lead Fashion." businessoffash-ion. March 31, 2014. http://www.businessoffashion. com/2014/03/op-ed-companies-best-software-willlead-fashion.html (accessed April 04, 2014).

[5] Raffaeli, Roberto, and Michele Germani. "Knowledgebased approach to flexible part de-sign." Journal of Engineering Design 21, no. 1 (2010): 7-29.

[6] Volino, Pascal, Frederic Cordier, and Nadia MagnenatThalmann. "From early virtual garment simulation to interactive fashion design." Computer-Aided Design, 2005: 593-608. 
[7] Liu, yong-Jin, Dong-Liang Zhang, and Matthew MingFai Yuen. "A survey on CAD methods in 3D garment design.” Computers in Industry 67, no. 6 (2010): 576-593.

[8] Fairhurst, Catherine. Advances in apparel production. Edited by The Textile Institute. Cam-bridge: Woodhead Puvlishing Limited, 2008.

[9] Tyler, D J. "Digital Printing Technology for textiles \& apparel." In Computer technology for tex-tiles \& apparel, by J Hu, 259-282. Cambridge: Woodhead Publishing, 2011.

[10] Wentzel, B. "Sampling the benefits of digital printing." Fashion Business International (Oct-Nov), 2002: 24-25.

[11] Istook, Cynthia L. "Enabling mass customization: computer-driven alteration methods." International Journal of Clothing Science and Technology 14, no. 1 (2002): 61-76.

[12] Hu, Zhi-Hua, Yong-Sheng Ding, Wen-Bin Zhang, and Qiao Yan. "An interactive co-evolutionary CAD system for garment pattern design." Computer-Aided Design 40 (2008): 1094-1104.

[13] Fang, Jing-Jing, and Yu Ding. "Expert-based customized pattern-making automation:Part I. Basic patterns." International Journal of Clothing Science and Technology 20, no. 1 (2008): 26-40.

[14] Volino, P, and N Magnenat-Thalmann. Virtual Clothing: Theory and Practice,. Springer, 2000.

[15] Chen, Y, X Zeng, M Happiette, P Bruniaux, R Ng, and W Yu. "Optimisation of garment design using fuzzy logic and sensory evaluation techniques." Engineering Applications of Artificial Intel-ligence 22, no. 2 (2009): 272-282.

[16] Ngai, E.W.T., S Peng, Paul Alexander, and karen K.L. Moon. "Decision support and intelli-gent systems in the textile and apparel supply chain: An academic review of research arti-cles." Expert Systems with Applications 41, no. 1 (2014): 81-91.

[17] Meng, Yuwei, P.Y. Mok, and Xiaogang Jin. "Computer aided clothing pattern design with 3D editing and pattern alteration." Computer-Aided Design 44, no. 8 (2012).

[18] Fontana, Marzia, Caterina Rizzi, and Umberto Cugini. "3D virtual apparel design for indus-trial applications." Computer-Aided Design 37 (2005): 609-622.
[19] Walter, Lutz, George-Alexander Kartsounis, and Stefano Carosio. Transforming Clothing Pro-duction into a Demand-Driven, Knowledge-Based, High-Tech Industry. London : SpringerLink, 2009.

[20] Vilumsone, Ausma, and Inga Dabolina. "Virtual Garment Creation." In Applications of Virtual Reality, by C S Lanyi, 49-67. 2012.

[21] Frumkin, S, S Bradley, and M Weiss. "Innovation and new product development in textiles." In New Product Development in Textiles - Innovation and production, by Lena Horne, 3-21. Cam-bridge: Woodhead Publishing, 2012.

[22] McCann, J. "The garment design process for smart clothing from fibre selection through to product launch." In Smart Clothes and Wearable Technology, by J McCann and D Bryson, 70-94. Elsevier, 2009.

[23] Pailes-Friedman, Rebeccah. What Is The Future Of Fabric? These Smart Textiles Will Blow Your Mind. Edited by Forbes. July 05, 2014. http://www.forbes. $\mathrm{com} / \mathrm{sites} /$ forbesstylefile/2014/05/07/what-is-thefuture-of-fabric-these-smart-textiles-will-blow-yourmind/ (accessed July 18, 2014).

[24] Hurford, R D. "Types of smart clothes and wearbale technology." In Smart clothes and Weara-ble Technology, by J McCann and D Bryson, 25-44. Elsevier, 2009.

[25] Van Langenhove, Lieva, and Carla Hertleer. "Smart Clothing: a new life." International Journal of Clothing Science and Technology 16, no. 1/2 (2004): 63-72.

[26] Ji, Yong Gu, and Kwangil Lee. "Standardization for Smart Clothing Technology." In Smart Clothing Technology Applications, by Gilsoo Cho, 60-86. NY: Taylor \& Francis, 2010.

[27] Cho, Gilsoo, Seungsin Lee, and Jayoung Cho. "Review and Reppraisal of Smart Clothing." In Smart Clothing: Technology and Applications, edited by Gilsoo Cho, 2-12. USA: Taylor and Fran-cis Group, 2010.

[28] McCann, J. "End User based design of innovative smart clothing." In Smart Clothes and Weara-ble Technology, by J McCann and D Bryson, 45-66. North America: Woodhead Publishing, 2009

[29] Ariyatum, B, R Holland, D Harrison, and T Kaz. "The future design direction of Smart Cloth-ing and development." Journal of Textile Institute 96, no. 4 
(2005): 199-212..

[30] Sonderegger, A, and S Juergen. "The influence of design aesthetics in usability testing: Ef-fects on user performance and perceived usability." Applied Ergonomics 41 (2010): 403-410.

[31] Suh, MinJoung, Katherine E Carroll, and Nancy L
Cassill. "Critical Review on Smart Clothing Product Development." Journal of Textile and Apparel, Technology and Management 6, no. 4 (2010): 1-18.

[32] Ugur, Secil. Wearing Embodied Emotions: A Practice Based Design research on Wearable Technolo-gy. Milano: Springer Milan, 2013. 